\title{
Ação da pancreatina na obtenção de hidrolisados protéicos de soro de leite com elevado teor de oligopeptídeos
}

\author{
Eliza Augusta Rolim Biasutti, Wendel de Oliveira Afonso, Carlos de Oliveira Lopes Junior, José \\ Virgílio Coelho, Viviane Dias Medeiros Silva, Marialice Pinto Coelho Silvestre*
}

Departamento de Alimentos, Faculdade de Farmácia, Universidade Federal de Minas Gerais

*Correspondência:

M.P.C. Silvestre

Departamento de Alimentos

Faculdade de Farmácia

Universidade Federal de Minas Gerais

Avenida Antônio Carlos, 6627

31270-901 - Belo Horizonte -

MG, Brasil

E-mail: malice@farmacia.ufmg.br
Vários hidrolisados enzimáticos de soro de leite foram preparados visando a elevação do teor de oligopeptídeos e a redução de custos para produção em larga escala. Para isso, empregou-se a pancreatina e alguns parâmetros hidroliticos como o tempo de reação (5, 10 e 15h), a relação $E: S(1: 100,2: 100$ e 4:100) e a concentração do substrato (10 e 15\%) foram testados. Os hidrolisados foram fracionados por cromatografia liquida de alta eficiência de exclusão molecular (SE-HPLC) e, para a quantificação dos componentes das frações cromatográficas, empregou-se o método rápido da Área Corrigida da Fração. Para os parâmetros estudados, observou-se efeito benéfico sobre o perfil peptídico, sendo que o melhor resultado, associado, principalmente, ao maior teor de oligopeptideos (49\%) e ao menor conteúdo de aminoácidos livres (22\%), foi obtido quando se empregou a concentração do substrato a 10\%, a relação E:S de 4:100 e o tempo de reação de 10h.

\section{Unitermos}

- Hidrolisados protéicos/ obtenção

- Pancreatina

- Soro de leite

- Oligopeptídeos

- Perfil peptídico

\section{INTRODUÇÃO}

Tradicionalmente, o soro era considerado pelos produtores de queijo como um subproduto da fabricação, com baixo ou nenhum valor comercial. Porém, esta visão mudou com a descoberta de propriedades funcionais e bioativas de seus componentes (Walzen et al., 2002), principalmente das proteínas, que têm sido apontadas como nutrientes portadores de atividade funcional, capazes de modular algumas respostas fisiológicas do organismo animal (Pacheco et al., 2006; Sgarbieri, 2004; Gauthier, Pouliot, 2003; Pihlanto-Lappällä, 2001).

Entretanto, a despeito das várias possibilidades de utilização do soro, que têm sido descobertas nos últimos 50 anos, aproximadamente metade da produção mundial de soro é descartada em efluentes sem qualquer tratamento. Desta forma, devido a sua alta demanda bioquímica de oxigênio (DBO), associada, principalmente, à presença de lactose e proteínas, constitui-se num forte agente de poluição ambiental (Siso, 1996; Cheryan, 1998).

O tratamento enzimático contribui para a melhoria das propriedades físicas, químicas, funcionais, organolépticas e nutricionais das proteínas, atuando, particularmente, nas características de absorção protéica. Diversos autores têm demonstrado que fórmulas contendo um elevado teor de oligopeptídeos, especialmente de di- e tripeptídeos, são utilizadas mais efetivamente do que uma mistura equivalente de aminoácidos livres, apresentando, 
assim, maior valor nutritivo (Keohane et al., 1985; Grimble et al., 1986; Rérat, 1993; Boza et al., 2000).

A avaliação dos teores de peptídeos em hidrolisados protéicos envolve, inicialmente, o fracionamento das amostras. Neste sentido, várias técnicas cromatográficas têm sido descritas na literatura, mas estas apresentam inúmeros inconvenientes, tais como interações entre o soluto e a fase estacionária e a ineficiência em separar os pequenos peptídeos (Lemieux et al., 1991; Schimidt, Poll, 1991; Davis, Lee, 1992; Golovchenko et al., 1992; Visser et al., 1992).

Silvestre et al. (1994a) desenvolveram um método eficiente para fracionamento e quantificação dos peptídeos, empregando uma coluna cromatográfica de exclusão molecular contendo o complexo poli (2-hidroxietilaspartamido)-sílica (PHEA), que lhes possibilitou separar peptídeos com massas moleculares menores do que $1000 \mathrm{Da}$, sendo este método empregado no presente trabalho.

Em diversos estudos o perfil peptídico de hidrolisados enzimáticos de diferentes fontes protéicas (caseína, soro de leite e leite em pó) foi determinado a fim de se avaliar a composição em peptídeos e aminoácidos livres (Morato et al., 2000; Carreira et al., 2004; Lopes et al., 2005; Morais et al., 2005; Soares et al., 2006; Barbosa et al., 2004; De Marco et al., 2005; Silva et al., 2005; Delvivo et al., 2006).

Este trabalho teve como objetivo otimizar as condições hidrolíticas, a fim de reduzir os custos para adaptação em escala industrial e obter hidrolisados de soro de leite com elevado teor de di- e tripeptídeos e peptídeos médios (500Da), bem como com baixos teores de grandes peptídeos (>1000Da) e de aminoácidos livres.

\section{MATERIAL E MÉTODOS}

\section{Material}

O soro de leite em pó (Kerrylac 700), parcialmente desmineralizado, foi fornecido pela Kerry do Brasil Ltda (Três Corações, MG, Brasil). A enzima pancreatina (Corolase PP), fornecida pela AB Enzymes ${ }^{\circledR}$ (Barueri, SP, Brasil), é uma enzima mista, de origem animal (pâncreas suíno), atividade $2000.000 \mathrm{LVE} / \mathrm{g}$, estável em pH neutro ou ligeiramente alcalino, $\mathrm{pH}$ ótimo entre 7 e 9 com temperatura ótima entre $35-50^{\circ} \mathrm{C}$.

Um agitador magnético (Fisatom, modelo 752A) com temperatura controlada e agitação constante foi utilizado para homogeneizar a mistura. Um liofilizador (Freeze Dry System / FreeZone 4,5, model 77500, LABCONCO) foi usado para secar as amostras. O sistema de cromatografia líquida de alta eficiência (HPLC), usado no fracionamento dos hidrolisados protéicos era constituído por uma coluna cromatográfica PHEA [poli-(2-hidroxietilaspartamida)-sílica], 250 x 9,4 mm, 5 mm e $200 \AA$ (PolylC, Columbia, MD, USA), uma bomba isocrática e um detector espectrofotométrico UV-VIS (série HP1100, Waldbronn, Alemanha), acoplado a um computador com software (HPchemstation, Avondale, USA). A água usada no cromatógrafo foi purificada em Sistema de Purificação (Áries Vaponics, Rockland, USA). Todos os reagentes utilizados eram de grau analítico.

\section{Determinação da composição química do soro de leite}

A composição química do soro de leite foi determinada segundo os métodos descritos na AOAC (1995). A umidade foi determinada pelo método de secagem em estufa ventilada (Quimis Q-314M242, série 020, Diadema, SP) a $105^{\circ} \mathrm{C}$ até peso constante; as cinzas, por incineração, em mufla a $550^{\circ} \mathrm{C}$; os lipídeos, por extração com éter etílico (Soxhlet modificado, Quimis Q-308G26, série 018, Diadema, SP); as proteínas foram determinadas pelo método de micro-Kjeldahl; os carboidratos, por diferença. $\mathrm{O}$ fator de conversão de nitrogênio para proteína usado foi 6,38 (Nielsen, 1998).

\section{Preparo dos hidrolisados enzimáticos do soro de leite}

Foram preparados 18 hidrolisados enzimáticos utilizando-se a pancreatina. As soluções a 10\% e 15\% (p/v) de soro de leite tiveram seu pH ajustado para 7,0 $\mathrm{com} \mathrm{Na}_{2} \mathrm{CO}_{3}$ a $3 \mathrm{~mol} / \mathrm{L}$ e foram colocadas em banho de óleo a $50^{\circ} \mathrm{C}$, sob agitação contínua. A enzima foi, então, adicionada em quantidade suficiente para se obter a relação enzima: substrato (E:S) desejada. Após 5, 10 e 15h de hidrólise, a reação foi interrompida por meio do aumento da temperatura para $85^{\circ} \mathrm{C}$ por $20 \mathrm{~min}$. Os hidrolisados obtidos foram liofilizados. Algumas condições de hidrólise estão apresentadas na Tabela I.

\section{Caracterização do perfil peptídico dos hidrolisados de soro de leite}

Esta caracterização foi realizada em duas etapas: fracionamento dos peptídeos, de acordo com o tamanho da cadeia, e sua posterior quantificação.

O fracionamento dos peptídeos foi realizado por cromatografia liquida de alta eficiência de exclusão molecular (SE-HPLC) em coluna PHEA, conforme descrito por Silvestre et al. (1994a). As amostras foram dissolvidas em uma concentração de $1 \mathrm{~g} \%$ (p/v) na fase móvel 
TABELA I - Variáveis hidrolíticas empregadas no preparo de hidrolisados protéicos de soro de leite.

\begin{tabular}{lccc}
\hline Hidrolisados & Concentração do substrato $(\mathrm{p} / \mathrm{v})$ & $\mathrm{E}: \mathrm{S}$ & Tempo de hidrólise $(\mathrm{h})$ \\
\hline P1 & 10 & $1: 100$ & 5 \\
P2 & 10 & $2: 100$ & 5 \\
P3 & 10 & $4: 100$ & 5 \\
P4 & 10 & $1: 100$ & 10 \\
P5 & 10 & $2: 100$ & 10 \\
P6 & 10 & $4: 100$ & 10 \\
P7 & 10 & $1: 100$ & 15 \\
P8 & 10 & $2: 100$ & 15 \\
P9 & 10 & $4: 100$ & 15 \\
P10 & 15 & $1: 100$ & 5 \\
P11 & 15 & $2: 100$ & 5 \\
P12 & 15 & $4: 100$ & 5 \\
P13 & 15 & $1: 100$ & 10 \\
P14 & 15 & $2: 100$ & 10 \\
P15 & 15 & $4: 100$ & 10 \\
P16 & 15 & $1: 100$ & 15 \\
P17 & 15 & $2: 100$ & 15 \\
P18 & 15 & $4: 100$ & 15 \\
\hline ES & 15 & & \\
\hline
\end{tabular}

$\mathrm{E}: \mathrm{S}=$ relação enzima substrato

(ácido fórmico a $0,05 \mathrm{~mol} / \mathrm{L}, \mathrm{pH} 2,5$ ) e submetidas à cromatografia à temperatura ambiente, sob condições isocráticas, a um fluxo de $0,5 \mathrm{~mL} / \mathrm{min}$, durante $35 \mathrm{~min}$, sendo que o volume injetado foi de $20 \mathrm{~mL}$. A fase móvel foi filtrada, através de membrana de $0,45 \mathrm{~mm}$, e desgaseificada imediatamente antes do uso. As frações foram separadas de acordo com o tempo de eluição, sendo $F 1$, de 11,5 a 16,0 min (peptídeos grandes, com mais de 7 resíduos de aminoácidos); F2, de 16,0 a 19,5 min (peptídeos médios, entre 4 e 7 resíduos); F3, de 19,5 a 20,5 min (di- e tripeptídeos); e F4, de 20,5 a 32,0 min (aminoácidos livres). O método rápido da Área Corrigida da Fração (ACF), desenvolvido por Silvestre et al. (1994b), foi utilizado para quantificar os peptídeos e aminoácidos livres presentes nos hidrolisados do soro de leite. Resumidamente, foram preparados cinco hidrolisados padrão (dois com tripsina e três com pancreatina) que foram fracionados por HPLC de exclusão molecular em coluna PHEA. As quatro frações obtidas foram coletadas (Coletor de Frações, modelo CF-1, Spectrum/Chrom, Houston, TX, EUA) sendo que o solvente foi removido, de cada fração, em evaporador Centrivap (modelo 78100-00D, Labconco, Kansas City, MI, EUA). Posteriormente, as frações foram submetidas à análise de aminoácidos. O cálculo da ACF foi realizado por meio de fórmulas desenvolvidas por Silvestre et al. (1994b), após a multidetecção das frações a 230nm, 280nm e $300 \mathrm{~nm}$, para se eliminar a interferência devida à absor- ção dos aminoácidos aromáticos. Traçou-se, então, uma curva padrão, plotando-se ACF em função do teor de aminoácidos.

\section{Análise estatística}

Todos os experimentos foram feitos em 3 repetições e as análises realizadas em triplicata. Para a avaliação das diferenças entre as médias dos teores de peptídeos e aminoácidos livres das frações cromatográficas dos hidrolisados de soro de leite foram realizadas a Análise de Variância (ANOVA fator único) e o Teste de Duncan $(\mathrm{p} \leq 0,05)$, (Pimentel-Gomes, 2000).

\section{RESULTADOS E DISCUSSÃO}

\section{Composição química do soro de leite em pó}

Diversos fatores como raça das vacas, alimentação (plano de nutrição e forma física da ração), temperatura ambiente, manejo e intervalo entre as ordenhas, produção de leite e infecção da glândula mamária, podem interferir na composição do leite e, conseqüentemente, na do soro (EMBRAPA, 2006). Apesar disso, observa-se na Tabela II, que para proteínas, os teores encontrados neste estudo estão próximos dos valores publicados pela USDA (2006), como também dos citados por Silva et al. (2005). Já o valor de lipídeos está mais 
TABELA II - Composição química do soro de leite em pó.

\begin{tabular}{lccc}
\hline Componentes & $\begin{array}{c}\text { Valores } \\
\text { obtidos }^{1}\end{array}$ & $\begin{array}{c}\text { Silva } \text { et al. } \\
(2005)\end{array}$ & $\begin{array}{c}\text { USDA } \\
(2006)^{2}\end{array}$ \\
\hline Umidade $(\mathrm{g} \%)$ & 2,63 & 3,51 & 3,19 \\
Proteínas $(\mathrm{g} \%)$ & 13,54 & 11,82 & 12,93 \\
Lipídeos $(\mathrm{g} \%)$ & 0,75 & 0,85 & 1,07 \\
Cinzas totais $(\mathrm{g} \%)$ & 5,11 & 8,72 & 8,35 \\
Açúcares totais (g\%) & 77,97 & 67,47 & 74,46 \\
\hline
\end{tabular}

${ }^{1}$ Valores obtidos no soro de leite utilizado no experimento. ${ }^{2}$ USDA National Nutrient Database for Standard Reference, Release 19, 2006.

próximo do encontrado por Silva et al. (2005).

Foi utilizado no experimento soro parcialmente desmineralizado, o que explica o teor de cinzas, que é inferior aos relatados na literatura consultada, obtido no presente trabalho.

\section{Caracterização dos hidrolisados de soro de leite}

\section{Perfil peptídico dos hidrolisados protéicos}

Os hidrolisados protéicos foram separados em quatro frações (F1, F2, F3 e F4) (Silvestre et al., 1994a). A fração F1 corresponde aos peptídeos com mais de 7 resíduos de aminoácidos, a fração $\mathrm{F} 2$ aos peptídeos médios contendo de 4 a 7 resíduos de aminoácidos, a fração F3 contém os di- e tripeptídeos e a fração F4 os aminoácidos livres. A título de exemplo, o perfil cromatográfico do hidrolisado S1, a 230 nm, está apresentado na Figura 1.
A técnica de SE-HPLC, utilizada no presente traba1ho, foi eficiente na caracterização de hidrolisados protéicos, especialmente quando o interesse está voltado para o fracionamento de peptídeos de baixas massas moleculares, ou seja, inferiores a 1000Da.

Técnicas como a eletroforese em gel de poliacrilamida-sódio dodecil sulfato (SDS-PAGE) (Schimidt, Poll, 1991; Schimidt, Markwijk, 1993; Gallagher et al., 1994) a cromatografia de exclusão molecular (SEC) (Deeslie, Cheryan, 1991), a HPLC capilar (Davis, Lee, 1992), a HPLC de troca de iônica (AE-HPLC) (Dizdaroglu, 1985) e a HPLC de exclusão molecular (SE-HPLC) empregando coluna TSK G-2000 SW (Lemieux et al., 1991) e coluna Superose -12HR 10/30 (Golovchenko et al., 1992; Visser et al., 1992) podem ser utilizadas para o fracionamento dos peptídeos de hidrolisados protéicos.

Entretanto, ao contrário da técnica aqui utilizada, a maioria destes métodos apresenta uma série de inconvenientes como, a dificuldade de separar os peptídeos de acordo com o tamanho da cadeia, sendo observada a superposição de compostos com pesos moleculares diferentes, relatada por Lemieux et al. (1991) empregando a SEHPLC com uma coluna TSK G-2000 SW e Davis \& Lee (1992) empregando a HPLC capilar. Além disso, empregando a SDS-PAGE, Schimidt e Poll (1991), relataram a dificuldade de detectar pequenos peptídeos $(<2000 \mathrm{Da})$ pela técnica utilizada uma vez que os peptídeos, devido à fixação insuficiente, são removidos durante os procedimentos de revelação e lavagem do gel.

Também utilizando SE-HPLC, porém com uma coluna Superose-12HR 10/30, Visser et al. (1992) e Golovchenko et al. (1992) verificaram a ocorrência de

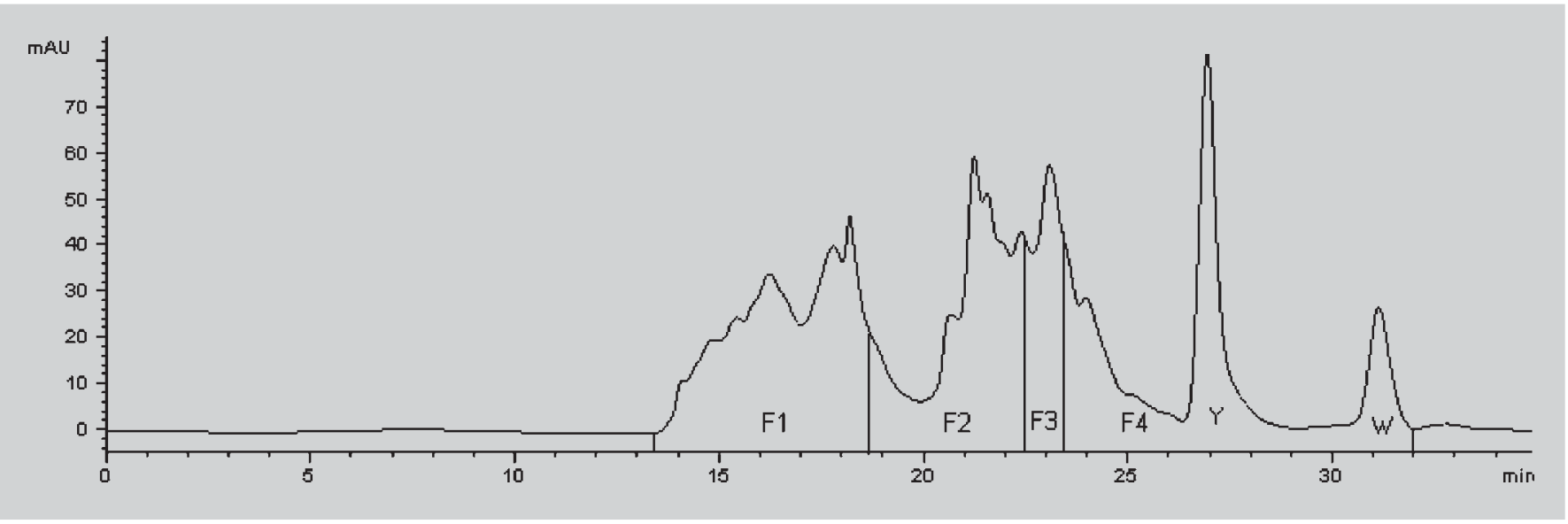

FIGURA 1 - Perfil cromatográfico do hidrolisado P1 a $230 \mathrm{~nm}$. F1: grandes peptídeos ( $>7$ resíduos de aminoácidos); F2: médios peptídeos (4 a 7 resíduos de aminoáciods); F3: di-e tripeptídeos; F4: aminoácidos livres. Y= pico da tirosina, $\mathrm{W}=$ pico do triptofano. Hidrolisado $\mathrm{P} 1=$ substrato a $10 \%$; tempo de hidrólise $=5 \mathrm{~h}$; relação $\mathrm{E}: \mathrm{S}=1 \%$. 
interações eletrostáticas e/ou hidrofóbicas entre os solutos e a fase estacionária.

Teor de peptídeos e aminoácidos livres dos hidrolisados

Observa-se na Tabela III que, para 7 hidrolisados (P1, P2, P9, P10, P11, P12 e P14), a distribuição de peptídeos e de aminoácidos livres foi semelhante, uma vez que não foram observadas diferenças significativas para os valores das quatro frações cromatográficas.

O hidrolisado P6 apresentou o melhor perfil peptídico, pois seu conteúdo de peptídeos com massa molecular média de $500 \mathrm{Da}(36,56 \%)$ foi o maior e o de aminoácidos livres $(22,02 \%)$ o menor, dentre todas as amostras analisadas. Além disso, seu teor de di- e tripeptídeos $(12,42 \%)$ foi semelhante ao dos outros hidrolisados.

A ação da pancreatina sobre o perfil peptídico de hidrolisados de soro de leite foi, anteriormente, avaliada em dois estudos, no mesmo laboratório do presente trabalho, mas utilizando-se condições diferentes para o preparo dos hidrolisados e o emprego da enzima.

Assim, no primeiro estudo, a pancreatina foi imobilizada em carvão ativado, antes de se proceder a hidrólise do soro do leite. Em seguida, fez-se a caracterização do perfil peptídico dos hidrolisados, cujo melhor resultado se mostrou inferior ao do hidrolisado P6 aqui obtido, com relação aos teores de grandes peptídeos $(58 \%)$ e de peptídeos médios (25\%) (Silva et al., 2005). A única vantagem da imobilização da pancreatina, em relação ao presente trabalho, refere-se ao baixo teor de aminoácidos livres (2\%), já que o de di- e tripeptídeos foi semelhante (15\%).

No segundo estudo, após a ação da pancreatina, os hidrolisados do soro de leite foram passados por uma coluna de carvão ativado e por uma membrana de ultrafiltração (UF) (corte 1000Da) e, posteriormente, caracterizou-se o perfil peptídico. Os melhores resultados obtidos foram superiores aos do presente trabalho, especialmente com relação aos teores de di- e tripeptídeos (21\%) e grandes peptídeos (16\%) (Delvivo et al., 2006). Este fato pode ser explicado pela utilização da UF, porém esta técnica apresenta a desvantagem de encarecer o processo, dificultando a sua aplicação em larga escala. Além disso, foi utilizada no estudo uma concentração de substrato cerca de 10 vezes menor do que a empregada no presente trabalho (1,06\%), o que eleva em demasia os custos do processo.

Todos os valores são apresentados em \% nmols das quatro frações. Os resultados representam a média das triplicatas. Médias indicadas por números iguais não diferem entre si a 5\% de significância na comparação de diferentes frações de um mesmo hidrolisado (linha). Médias indicadas por letras iguais não diferem entre si a $5 \%$ de significância na comparação de uma mesma fração para diferentes hidrolisados (coluna).

TABELA III - Teor de peptídeos e de aminoácidos livres nas frações cromatográficas dos hidrolisados de soro de leite obtidos pela ação da pancreatina.

\begin{tabular}{|c|c|c|c|c|}
\hline Hidrolisados & F1 & F2 & F3 & $\mathrm{F} 4$ \\
\hline P1 & $22,44^{\mathrm{d} / 3}$ & $26,26^{\mathrm{cde} / 2}$ & $10,24^{\mathrm{abc} / 4}$ & $41,04^{\mathrm{fg} / 1}$ \\
\hline P2 & $23,34^{\mathrm{cd} / 3}$ & $26,52^{\mathrm{cde} / 2}$ & $10,45^{a b c / 4}$ & $39,68^{g / 1}$ \\
\hline P3 & $8,69^{\mathrm{h} / 3}$ & $21,51^{\mathrm{i} / 2}$ & $8,26^{\mathrm{cd} / 3}$ & $61,52^{a / 1}$ \\
\hline P4 & $19,55^{\mathrm{ef} / 3}$ & $31,29^{\mathrm{b} / 2}$ & $5,35^{\mathrm{e} / 4}$ & $43,78^{e / 1}$ \\
\hline P5 & $18,71^{\mathrm{f} / 3}$ & $23,78^{\mathrm{fgh} / 2}$ & $10,10^{\mathrm{abc} / 4}$ & $47,39 \mathrm{~d} / 1$ \\
\hline P6 & $28,93 \mathrm{~b} / 2$ & $36,56^{a / 1}$ & $12,42^{a / 4}$ & $22,02 \mathrm{i} / 3$ \\
\hline P7 & $14,37^{\mathrm{g} / 3}$ & $16,58^{\mathrm{j} / 2}$ & $6,20 \mathrm{de} / 4$ & $62,83^{a / 1}$ \\
\hline P8 & $31,48^{a / 1}$ & $28,05^{\mathrm{c} / 2}$ & $9,67 \mathrm{bc} / 3$ & $30,78^{\mathrm{h} / 1}$ \\
\hline P9 & $21,65 \mathrm{de} / 3$ & $27,68^{\mathrm{cd} / 2}$ & $10,13^{a b c / 4}$ & $40,53 \mathrm{fg} / 1$ \\
\hline $\mathrm{P} 10$ & $23,85^{\mathrm{cd} / 3}$ & $28,50^{\mathrm{c} / 2}$ & $8,62^{\mathrm{c} / 4}$ & $39,01^{\mathrm{g} / 1}$ \\
\hline P11 & $23,15^{\mathrm{d} / 2}$ & $24,83^{\mathrm{efg} / 2}$ & 9,35 bc/3 & 42,64 ef/1 \\
\hline P12 & $22,12^{d / 3}$ & $25,47 \operatorname{def} / 2$ & $10,20^{\mathrm{abc} / 4}$ & 42,19 ef $/ 1$ \\
\hline P13 & $25,66^{\mathrm{c} / 2}$ & $25,08^{e f / 2}$ & $5,11^{\mathrm{e} / 3}$ & $44,13^{\mathrm{e} / 1}$ \\
\hline P14 & $21,83^{\mathrm{de} / 3}$ & $27,01^{\mathrm{cde} / 2}$ & $11,34^{\mathrm{ab} / 4}$ & $39,80^{g / 1}$ \\
\hline P15 & $15,01 \mathrm{~g} / 3$ & $22,62 \mathrm{ghi} / 2$ & $9,61 \mathrm{bc} / 4$ & $52,74^{\mathrm{c} / 1}$ \\
\hline P16 & $15,29 \mathrm{~g} / 3$ & $21,80 \mathrm{hi} / 2$ & $5,67 \mathrm{e} / 4$ & $57,21^{b / 1}$ \\
\hline P17 & $19,10^{\mathrm{f} / 3}$ & $26,71^{\mathrm{cde} / 2}$ & $10,34^{\mathrm{abc} / 4}$ & $43,84^{\mathrm{e} / 1}$ \\
\hline P18 & $17,82^{\mathrm{f} / 3}$ & $27,62^{\mathrm{cd} / 2}$ & $10,44^{\mathrm{abc} / 4}$ & $44,10^{\mathrm{e} / 1}$ \\
\hline
\end{tabular}




\section{Comparação entre os diferentes tratamentos enzimáticos}

Os resultados aqui obtidos serão comparados com os relatados na literatura para a ação da pancreatina sobre o perfil peptídico do soro de leite, porém, nesses estudos foram empregadas condições diferentes das utilizadas no presente trabalho no que se refere ao preparo dos hidrolisados e ao emprego da enzima.

Todos os parâmetros foram analisados levando-se em consideração a redução de custos do processo para adaptação em escala industrial. O aumento da concentração do substrato está associado à redução da quantidade de água e, conseqüentemente, do tempo gasto no processo de secagem; a redução da relação E:S está associada ao emprego de menor quantidade de enzima necessária para a hidrólise; a redução do tempo de hidrólise está relacionada à diminuição de contaminação bacteriana, à redução de formação de produtos de degradação, além de menor consumo de energia.

\section{Efeito da concentração do substrato}

Para analisar o efeito da concentração inicial do soro de leite sobre o perfil peptídico dos hidrolisados protéicos, devem ser comparados os seguintes hidrolisados: P1 com P10, P2 com P11, P3 com P12, P4 com P13, P5 com P14, P6 com P15, P7 com P16, P8 com P17 e P9 com P18, uma vez que os parâmetros tempo de hidrólise, relação E:S, $\mathrm{pH}$ e temperatura são mantidos constantes. Em cada uma das partes A, B e C da Figura 2 estão apresentados três destes grupos de hidrolisados.

Observa-se na Figura 2 que a vantagem da utilização de uma maior concentração do substrato ocorreu em alguns casos e relaciona-se a elevação do teor de oligopeptídeos (P3 e P12; P5 e P14; P7 e P16) e a queda nos teores de grandes peptídeos (P6 e P15; P8 e P17; P9 e P18) e de aminoácidos livres (P3 e P12; P5 e P14; P7 e P16) ao aumentar a concentração de 10 para $15 \%$.

\section{Efeito da relação E:S}

A influência da relação E:S na ação da pancreatina sobre o soro de leite pode ser avaliada na Figura 3. No intuito de manter os demais parâmetros hidrolíticos constantes, a análise dos dados deve considerar seis grupos contendo, cada um, três hidrolisados: grupo 1 (P1, P2 e P3); grupo

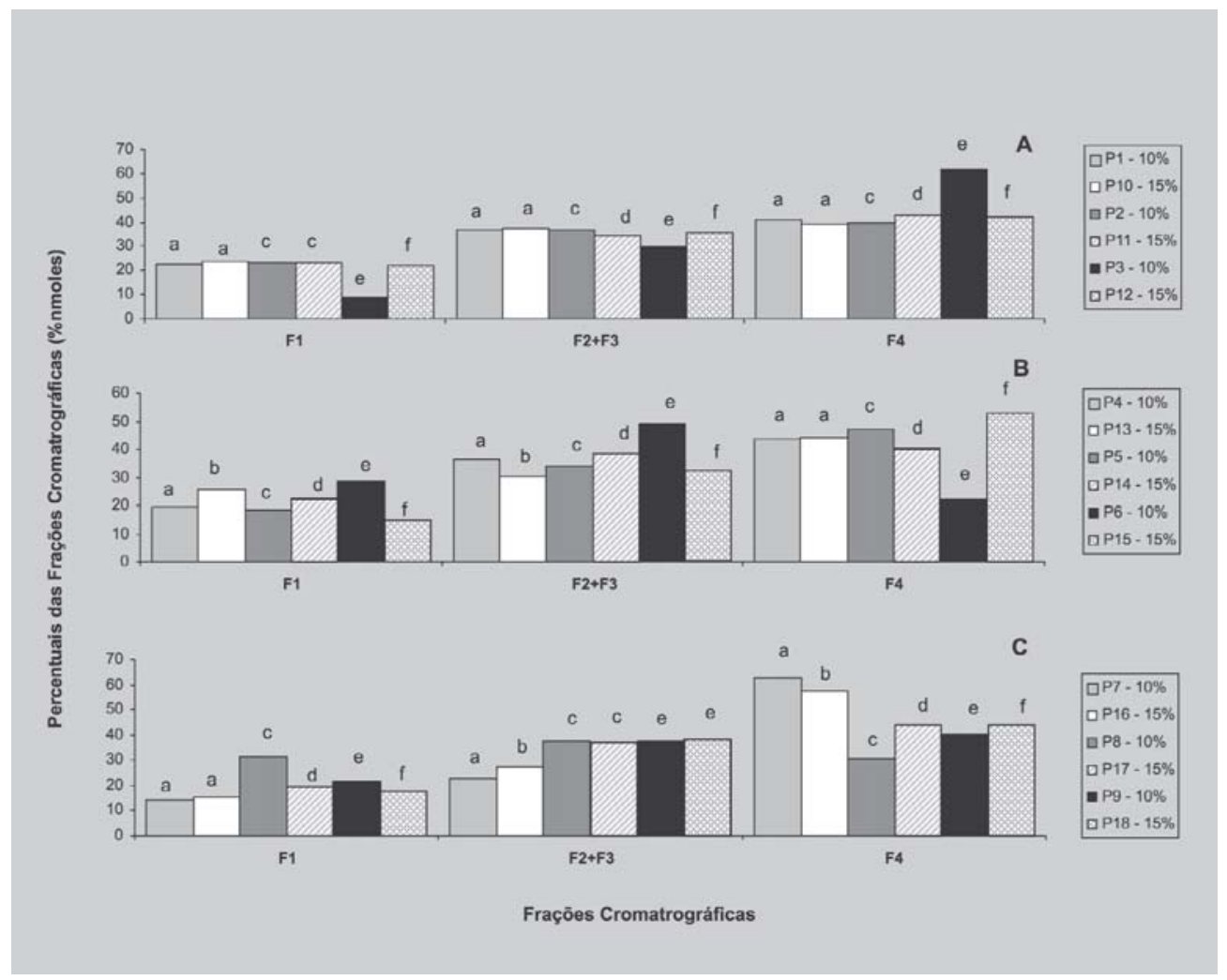

FIGURA 2 - Efeito da concentração do substrato sobre o perfil peptídico de hidrolisados de soro de leite. Concentrações utilizadas: 10\% (P1, P2, P3, P4, P5 P6, P7, P8, P9) e 15\% (P10, P11, P12, P13, P14, P15, P16, P17, P18). F1: grandes peptídeos (> 7 resíduos de aminoácidos); F2+F3: oligopeptídeos (2 a 7 resíduos de aminoácidos); F4: aminoácidos livres. Os resultados representam a média das triplicatas. Para cada comparação, médias indicadas por letras iguais não diferem entre si a 5\% de probabilidade no caso de uma mesma fração para diferentes hidrolisados. 
2 (P4, P5 e P6); grupo 3 (P7, P8 e P9); grupo 4 (P10, P11 e P12) grupo 5 (P13, P14 e P15) e grupo 6 (P16, P17 e P18). A comparação entre esses grupos estão representados na Figura 3, subdividida em A (comparação entre os grupos 1 e 2), B (grupos 3 e 4) e C (grupos 5 e 6 ).

Observa-se que o efeito benéfico devido à utilização de uma menor relação E:S ocorreu em dois casos relacionados com a elevação do teor de oligopeptídeos quando a E:S passaou de 4:100 para 2:100 (P3 e P2; P15 e P14). e, em dois casos, ao passar de 2:100 para 1:100 (P5 e P4; P11 e P10). Além disso, a redução do teor de grandes peptídeos foi obtida em apenas um caso, quando passou de 4:100 para 2:100 (P6 e P5), e em dois casos quando a relação E:S passou de 2:100 para 1:100 (P8 e P7; P17 e P16). Os menores teores de aminoácidos livres foram obtidos em três casos quando a E:S caiu de 4:100 para 2:100 (P3 e P2; P9 e P8; P15 e P14) e em dois casos quando a E:S foi reduzida de 2:100 para 1:100 (P5 e P4; P11 e P10).

Em dois estudos empregando-se a pancreatina para hidrolisar o soro de leite, o efeito da redução da relação E:S sobre o perfil peptídico foi avaliado após o tratamento dos hidrolisados com carvão ativado para remoção de fenilalanina.
Assim, empregando-se esta enzima imobilizada em carvão ativado, observou-se que a utilização de uma relação E:S 100 vezes menor (de 1:100 para 0,01:100) foi benéfica para o perfil peptídico, tendo aumentado substancialmente o teor de oligopeptídeos (de 8 para $40 \%$ ) e reduzido drasticamente o conteúdo de aminoácidos livres (de 53 para 2\%) (Silva et al., 2005). No segundo estudo, a pancreatina foi usada em solução, e não foi observado qualquer efeito sobre o perfil peptídico, relacionado à utilização de uma menor relação E:S de 0,1:100 para 0,01:100 (Delvivo et al., 2006).

\section{Efeito do tempo de hidrólise}

A influência do tempo na ação da pancreatina sobre o soro de leite pode ser avaliada na Figura 4. No intuito de manter os demais parâmetros hidrolíticos constantes, a análise dos dados deve considerar seis grupos contendo, cada um, três hidrolisados: grupo 1 (P1, P4 e P7); grupo 2 (P2, P5 e P8); grupo 3 (P3, P6 e P9); grupo 4 (P10, P13 e P16) grupo 5 (P11, P14 e P17) e grupo 6 (P12, P15 e P18). A comparação entre esses grupos estão representados na Figura 4, subdividida em A (comparação entre os grupos 1 e 2), B (grupos 3 e 4 ) e C (grupos 5 e 6 ).

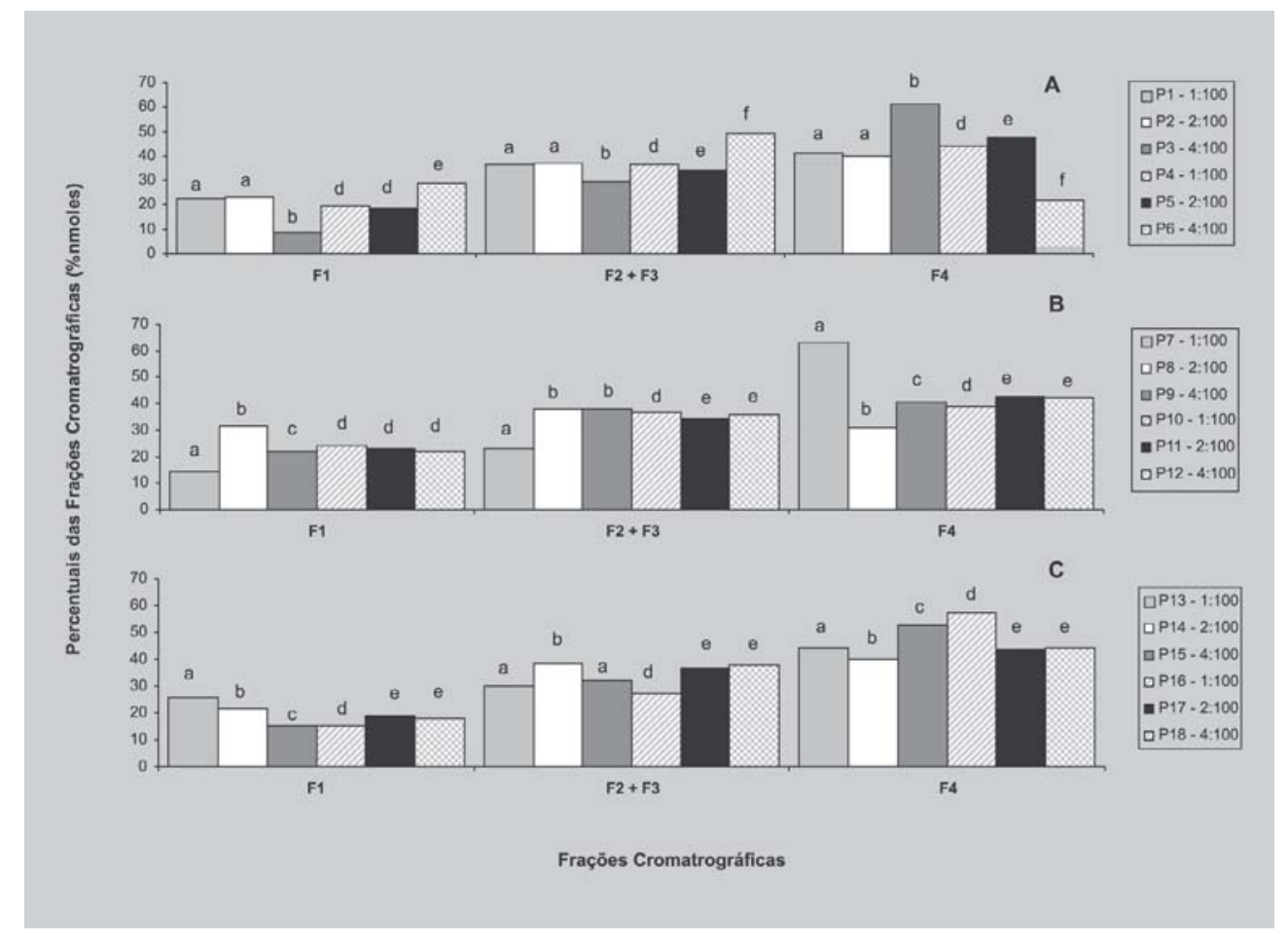

FIGURA 3 - Efeito da relação E:S sobre o perfil peptídico de hidrolisados de soro de leite. Relações E:S utilizadas: 1:100 (P1, P4, P7, P10, P13, P16), 2:100 (P2, P5, P8, P11, P14, P17) e 4:100 (P3, P6, P9, P12, P15, P18) F1: grandes peptídeos (> 7 resíduos de aminoácidos); F2+F3: oligopeptídeos (2 a 7 resíduos de aminoácidos); F4: aminoácidos livres. A: comparação entre os hidrolisados dos grupos 1 e 2. B: comparação entre os hidrolisados dos grupos 3 e 4. C: comparação entre os hidrolisados dos grupos 5 e 6 . Os resultados representam a média das triplicatas. Para cada comparação, médias indicadas por letras iguais não diferem entre si a 5\% de probabilidade no caso de uma mesma fração para diferentes hidrolisados. 


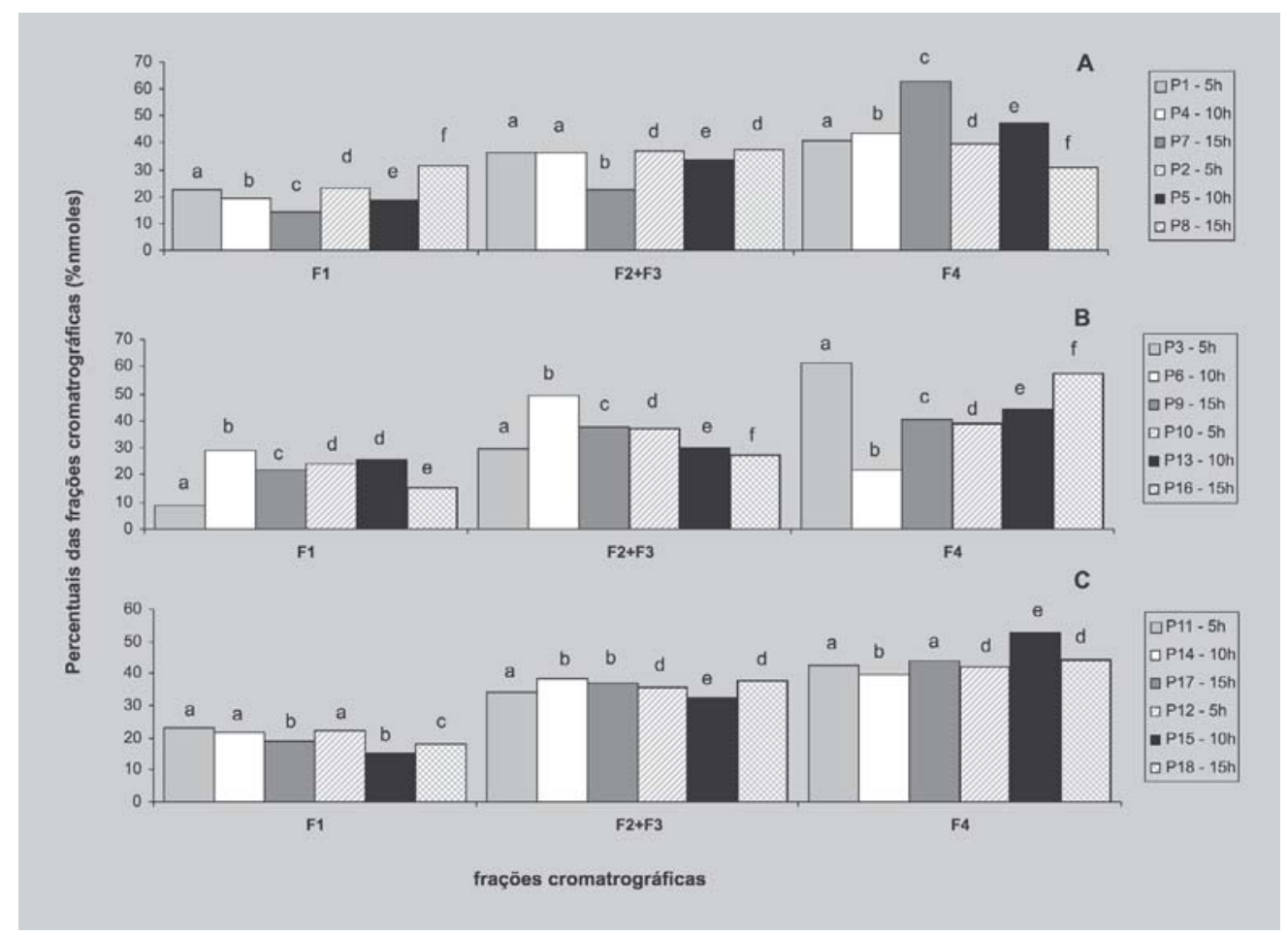

FIGURA 4 - Efeito do tempo de hidrólise sobre o perfil peptídico de hidrolisados de soro de leite. Tempos utilizados: 5h (P1, P2, P3, P10, P11, P12), 10h (P4, P5, P6, P13, P14, P15) e 15h (P7, P8, P9, P16, P17, P18). F1: grandes peptídeos (> 7 resíduos de aminoácidos); F2+F3: oligopeptídeos (2 a 7 resíduos de aminoácidos; F4: aminoácidos livres. A: comparação entre os hidrolisados dos grupos 1 e 2. B: comparação entre os hidrolisados dos grupos 3 e 4. C: comparação entre os hidrolisados dos grupos 5 e 6 . Os resultados representam a média das triplicatas. Para cada comparação, médias indicadas por letras iguais não diferem entre si a 5\% de probabilidade no caso de uma mesma fração para diferentes hidrolisados.

Observa-se que o efeito benéfico devido à utilização de um menor tempo de reação, associado com a elevação do teor de oligopeptídeos, ocorreu em três casos relacionados quando o tempo passou de 15 para $10 \mathrm{~h}$ (P7 e P4; P9 e P6; P16 e P13) e, em outros três, ao passar de 10 para $5 \mathrm{~h}$ (P5 e P2; P13 e P10; p15 e p12). Além disso, a redução do teor de grandes peptídeos foi obtida em dois casos quando o tempo passou de 15 para $10 \mathrm{~h}$ (P8 e P5; P18 e P15) e, em um caso, quando passou de 10 para 5 h (P6 e P3). Os menores teores de aminoácidos livres foram obtidos em quatro casos quando o tempo foi reduzido de 15 para $10 \mathrm{~h}(\mathrm{P} 7$ e P4; P9 e P6; P16 e P13; P17 e P14) e, em quatro casos, quando o tempo foi aumentado de 10 para $15 \mathrm{~h}(\mathrm{P} 4 \mathrm{e}$ P1; P5 e P2; P13 e P10; P15 e P12).

\section{CONCLUSÃO}

A ação da pancreatina foi eficiente na produção de hidrolisados de soro de leite com perfil peptídico adequado para uso em dietas especiais. Dentre as condições testadas, a que empregou a concentração do substrato de $10 \%$, a relação E:S de 4:100 e o tempo de hidrólise de 10h, pro- piciou o melhor resultado, tendo alcançado um teor de oligopeptídeos de 49\%. O efeito benéfico, associando os diversos parâmetros estudados (utilização de maior concentração do substrato e de menores relação E:S e do tempo de reação), com a redução dos custos de processo, foi observado em vários casos.

\section{ABSTRACT \\ Action of pancreatin for obtaining whey protein hydrolysates with high oligopeptide contents}

Several enzymatic hydrolysates of whey were prepared with the objective of increasing the oligopeptide content and reducing the cost of large scale production. Pancreatin was used and some hydrolytic parameters such as reaction time $(5,10$ and $15 \mathrm{~h})$, enzyme:substrate ratio (E:S) $(1: 100,2: 100$ and 4:100) and substrate concentration (10 and 15\%) were tested. The hydrolysates were fractionated by size-exclusion-HPLC and the rapid corrected fraction area method was used for quantifying the chromatographic fractions. The beneficial effect on the 
peptide profile was observed in several cases, and it was mainly associated with higher oligopeptide (49\%) and lower amino acid (22\%) contents, which were obtained for a substrate concentration of 10\%, E:S ratio of $4: 100$ and reaction time of $10 \mathrm{~h}$.

UNITERMS: Proteic hydrolysates/obtention. Pancreatin. Whey. Oligopeptides. Peptide profile.

\section{REFERÊNCIAS BIBLIOGRÁFICAS}

AOAC(ASSOCIATION OF OFFICIALAGRICULTURAL CHEMISTS) Official methods of analysis of AOAC international. 16 ed. Arlington: AOAC International, 1995. 2v.

BARBOSA, C. M. S.; MORAIS, H. A.; DELVIVO, F. M.; MANSUR, H. S.; OLIVEIRA, M. C.; SILVESTRE, M. P. C. Papain hydrolysates of casein: molecular weight profile and encapsulation in lipospheres. J. Sci. Food Agric., v.84, n.14, p.1891-1900, 2004.

BOZA, J. J.; MOËNNOZ, D.; VUICHOUD, J.; JARRET, A. R.; GAUDARD-DE-WECK, D.; BALLÈVRE, O. Protein hydrolysate vs free amino acid-based diets on the nutritional recovery of the starved rat. Eur. J. Nutr., v.39, p.237-243, 2000.

CARREIRA, R. L.; DE MARCO, L. M.; DIAS, D. R.; MORAIS, H. A.; SILVESTRE, M. P. C. Analysis of peptide profiles of casein hydrolysates prepared with pepsin, trypsin and subtilisin. Acta Farm. Bon., v.23, n.1, p.17-25, 2004.

CHERYAN, M. Ultrafiltration and Microfiltration Handbook. Illinois: Technomic Publishing Co, 1998. 527p.

DAVIS, M. T.; LEE, T. D. Analysis of peptide mixtures by capillary high performance liquid chromatography: A practical guide to small-scale separations. Prot. Sci., v.1, p.935-944, 1992.

DELVIVO, F. M.; VIEIRA, C. R.; BIASUTTI, E. A. R.; AFONSO, W. O.; SILVESTRE, M. P. C. Evaluating the effect of adsorption medium, hydrolytic parameters and ultrafiltration on the phenylalanine removal from pancreatic whey hydrolysates. Am. J. Food Technol., v.1, n.2, p.94-104, 2006.
DEESLIE, W. D; CHERYAN, M. Fractionation of soy protein hydrolysates using ultrafiltration membranes. $J$. Food Sci., v.57, n.2, p.26-31, 1991.

DIZDAROGLU, M. Weak anion-exchange high-performance liquid chromatography of peptides. J. Chromatogr., v.334, p.49-69, 1985.

EMBRAPA (EMPRESA BRASILEIRA DE PESQUISA AGROPECUÁRIA). Agência de informação Agronegócio do leite. Disponível em: < http:// www.agencia.cnptia.embrapa.br/Agencia8/AG01/arvore/ AG01_128_21720039243.html>.Acesso em: 20 set. 2006.

GALLAGHER, J.; KANEKANIAN, A. D.; EVANS, E. P. Hydrolysis of casein: a comparative study of two proteases and their peptide maps. Int. J. Food Sci. Tech., v.29, p.279-285, 1994.

GAUTHIER, S. F.; POULIOT, Y. Functional and biological properties obtained by enzymatic hydrolysis of whey proteins. J. Dairy Sci., v.86, p.78-87, 2003.

GOLOVCHENKO, N, KATAEVA, I. A, AKIMENKO, V.K. Analysis of $\mathrm{pH}$-dependent protein interactions with gel filtration medium. J. Chromatogr., v.591, n.4, p.121-128, 1992.

GRIMBLE, G. K.; KEOHANE, P. P.; HIGGINS, B. E.; KAMINSKI JUNIOR., M. V.; SILK, D. B. A. Effect of peptide chain length on amino acid and nitrogen absorption from two lactoalbumin hydrolysates in the normal human jejunum. Clin. Sci., v.71, n.1, p.65-69, 1986.

KEOHANE, P. P.; GRIMBLE, G. K.; BROWN, B.; SPILLER, R. C. Influence of protein composition and hydrolysis method on intestinal absorption of protein in man. Gut, v.26, p.907-913, 1985.

LEMIEUX, L.; PIOT, J. M., GUILLOCHON, D; AMIOT, J. Study of the efficiency of a mobile phase used in sizeexclusion HPLC for the separation of peptides from a casein hydrolysate according to their hydrodynamic volume. J. Chromatogr., v.32, p.499-504, 1991.

LOPES, D. C. F.; DELVIVO, F. M.; SILVESTRE, M. P. C. Hydrolysates of skim milk powder: peptide profiles for dietetic purposes. Brit. Food J., v.107, n.1, p.42-53, 2005. 
DE MARCO, L. M.; DELVIVO, F. M.; SILVA, V. D. M.; COELHO, J. V.; SILVESTRE, M. P. C. Uso do carvão ativado para remoção de fenilalanina de hidrolisados protéicos, obtidos pela ação da papaína imobilizada. Braz. J. Food Technol., v.8, n.3, p.210-219, 2005.

MORAIS, H. A.; DE MARCO, L. M.; OLIVEIRA, M. C.; SILVESTRE, M. P. C. Casein hydrolysates using papain: peptide profile and encapsulation in liposomes. Acta Alim., v.34, n.1, p.59-69, 2005.

MORATO, A. F.; CARREIRA, R. L.; JUNQUEIRA, R. G.; SILVESTRE, M. P. C. Optimization of casein hydrolysis for obtaining high contentes of small peptides: use of subtilisin and trypsin. J. Food Comp. Anal., v.13, p.843$857,2000$.

NIELSEN, S. S. Food Analysis . Gaithersburg: Aspen Publisher, 1998. 630 p.

PACHECO, M. T. B.; DIAS N. F. G.; BALDINI, V. L.; TANIKAWA, C.; SGARBIERI, V. C. Propriedades funcionais de hidrolisados obtidos a partir de concentrados protéicos do soro de leite. Ciênc. Tecnol. Aliment., v.25, n.2, p.333-338, 2005.

PIHLANTO-LEPP ÄLÄ, A. Bioactive peptides derived from bovine whey proteins: opioid and ace-inhibitory peptides. Trends Food Sci. Technol., v.11, p.347-356, 2001.

PIMENTEL-GOMES, F. Curso de estatística experimental. 14 ed. Piracicaba: Nobel, 2000. 477p.

RERAT, A. A. Nutritional supply of proteins and absorption of their hydrolysis products: consequences on metabolism Proc. Nutr. Soc., v.52, p.335-344, 1993.

SCHMIDT, D. G.; MARKWIJK, B. W. V. Enzymatic hydrolysis of whey proteins. Influence of heat treatment of a-lactalbumin and b- lactoglobulin on their proteolysis by pepsin and papain. Neth. Milk Dairy J., v.47, p.15-22, 1993

SCHMIDT, D. G, POLL, J. K. Enzymatic hydrolysis of whey proteins. Hydrolysis of a-lactoalbumin and $\beta$ lactoglobulin in buffer solutions by proteolytic enzymes. Neth. Milk Dairy J., v.45, n.4, p.225-240, 1991.

SGARBIERI, V.C. Propriedades fisiológicas-funcionais das proteínas do soro de leite. Rev. Nutr., v.17, n.4, p.397-409, 2004.
SGARBIERI, V.C. Proteínas em alimentos protéicos: propriedades, degradações, modificações. São Paulo: Varela, 1996. 517p.

SILVA, V. D. M.; DE MARCO, L. M.; DELVIVO, F. M.; AGUIAR, M. J. B.; COELHO, J. V.; SILVESTRE, M. P. C. Emprego da pancreatina imobilizada no preparo de hidrolisados de soro de leite com teor reduzido de fenilalanina. Alim. Nutr., v.16, n.1, p.21-31, 2005.

SILVESTRE, M. P. C., HAMON, M.; YVON, M. Analyses of protein hydrolysates. 1. Use of poly (2-hydroxyethylaspartamide)-silica column in size-exclusion chromatography for the fracionation of casein hydrolysates. J. Agric. Food Chem., v.42, n.12, p.27782782, 1994a.

SILVESTRE, M. P. C., HAMON, M., YVON, M. Analyses of protein hydrolysates. 2. Characterization of casein hydrolysates by a rapid peptide quantification method. $J$. Agric. Food Chem., v.42, n.12, p.2783-2789, 1994b.

SISO, M.I.G. The biotechnological utilization of cheese whey: a review. Biores. Technol., v.57, p.1-11, 1996.

SOARES, R. D. L.; BIASUTTI, E. A. R.; CAPOBIANGO, M.; VIEIRA, C. R.; SILVA, V. D. M.; JANUÁRIO, J. N. ; AGUIAR, M. J. B.; SILVESTRE, M. P. C. Preparation of enzymatic skim milk hydrolysates with low phenylalanine content. Acta Farm. Bon., v.25, n.3, p.325332, 2006.

USDA (UNITED STATES DEPARTMENT OF AGRICULTURE). Nutrient Data Laboratory. Disponível em:<http:// http://www.nal.usda.gov/fnic/ foodcomp/search/ > . Acesso em: 24 nov. 2006.

VISSER, S.; SLAGEN, C. J.; ROBBEN, A. J. P. M. Determination of molecular mass distributions of whey protein hydrolysates by high-performance size-exclusion chromatography. J. Chromatogr., v.599, p.205-209, 1992.

Recebido para publicação em 31 de janeiro de 2007. Aceito para publicação em 23 de outubro de 2007. 